\title{
Personalized medicine and genetic malpractice
}

\author{
Gary E. Marchant, PhD, JD' and Rachel A. Lindor, JD²
}

Angelina Jolie's recent revelation that she had prophylactic surgery to reduce her breast cancer risk after BRCA genetic testing has increased public interest in preventive genetic testing. This so-called "Angelina effect" exemplifies a growing consumer interest and medical uptake of genetic testing in response to the increased availability and utility of clinically relevant genetic data. The advent of next-generation DNA sequencing will further accelerate this trend toward increased reliance on genetic data in the health-care system, and health-care providers, in almost every specialty, will be required to have some familiarity with genetic data.

Yet, as the use and usefulness of genetic information in clinical decision making continues to expand, the specter of lawsuits against physicians and other health-care entities for genetic malpractice also becomes a reality. Consider the following three cases from the past year, which illustrate three major areas of genetic testing in which potential liability is a growing concern-cancer predisposition screening, prenatal testing, and pharmacogenomic profiling.

A woman from Connecticut sued her physician for failing to warn that her extensive family history of breast cancer suggested a genetic risk of ovarian cancer. The Connecticut Supreme Court recently upheld a $\$ 4$ million jury verdict to her after she went on to develop ovarian cancer. ${ }^{1}$

A couple from Oregon successfully sued their physicians and hospital for negligence in performing and interpreting prenatal genetic testing for Down syndrome. The jury awarded the parents $\$ 3$ million in damages after the child was born with Down syndrome. $^{2}$

A woman from California sued her health-care providers for prescribing carbamazepine without first recommending genetic testing as recommended by the label approved by the Food and Drug Administration for patients of Asian ancestry. The woman, who is of Asian descent, developed StevensJohnson syndrome after being prescribed the drug. Her case is currently in arbitration. ${ }^{3}$

It is too early to tell whether the initial wave of lawsuits against health-care providers for their alleged failure to recommend or properly interpret genetic testing will turn out to be a ripple, a rough chop, or a tidal wave. Of course, physicians are not the only potential target of such genetic malpractice lawsuits, as drug manufacturers, device makers, testing laboratories, health insurers, hospitals, genetic counselors, and even pharmacists face liability risks relating to genetic data or testing, although most of these potential targets often have effective defenses that shield them from liability. For example, drug manufacturers are protecting themselves from failure-to-warn claims by increasingly putting genetic information in the patient package insert, which shifts the liability exposure for warning patients about such risks to physicians under the learned intermediary doctrine. Healthcare payers and pharmacists often have statutory defenses that help limit their liability, which again are unavailing to physicians.

Thus, physicians have been the targets of most genetic malpractice lawsuits to date and are likely probably to be at the greatest risk going forward. As we enter the era of personalized medicine, noninvasive prenatal testing and whole-genome sequencing, several factors suggest that physicians, in particular, will face growing risks of legal claims for genetic malpractice. ${ }^{4}$

First, and most generally, history demonstrates that new medical technologies usually spur increases in medical malpractice litigation. ${ }^{5}$ In part, this is a reflection of the reality that the more a provider is capable of doing, the more he or she should do, and the more something can go wrong and lead to a lawsuit. For example, before the advent of renal dialysis, most patients with renal failure died with few lawsuits filed; however, after dialysis became available, many more patients survived, yet more patients also filed lawsuits based on mistakes in using the technology or because the expectations of patients outpaced the actual performance of the new technology. ${ }^{6}$ Similar trends have been documented surrounding the emergence of antiseptic practices, laparoscopic techniques and, now, even medical robotics. Moreover, when a new technology such as genetic testing is taken up by medical professionals unevenly, a gap develops between the care provided by early adopters versus that by late adopters, again providing an opening for liability based on the disparity in treatment, with both early adopters and late adopters facing potential risks for being too quick or not quick enough to adopt the new technology.

Second, and more unique to personalized medicine, there are significant disagreements about the scope and timing of the implementation of genetic testing in the clinical context. Some experts contend that many personalized medicine applications are ready to be used now, whereas others advocate for a more cautious approach. For example, there is disagreement on whether genetic testing should be required before prescribing drugs such as warfarin or clopidogrel. These types of disagreements provide rich fodder for litigation. Moreover, given the rapid pace at which technology and clinical applications are

${ }^{1}$ Center for Law, Science, Innovation, Arizona State University, Tempe, Arizona, USA; ${ }^{2}$ Mayo Clinic College of Medicine, Rochester, Minnesota, USA. Correspondence:

Gary E Marchant (gary.marchant@asu.edu)

Submitted 30 July 2013; accepted 7 August 2013; advance online publication 26 September 2013. doi:10.1038/gim.2013.142 
evolving, new standards of care and gaps between the practices of different physicians can emerge rapidly, again leading to divergent expert opinions about appropriate practices. As long as each side can present at least one credible expert who can point to peer-reviewed studies supporting their positions, such cases are likely to be presented to the jury, where the outcome will often be a toss-up dictated by the composition and inclinations of individual jurors.

Third, there are likely to be many actual or perceived victims of inadequate or erroneous applications of personalized medicine. Adverse drug effects, for example, are the sixth leading cause of death in the United States, accounting for over 100,000 fatalities per year, in addition to more than 2 million hospitalizations. ${ }^{7}$ Because genetic testing could arguably prevent a significant fraction of this mortality and morbidity, a large pool of potential plaintiffs will be available to trial lawyers who develop practices in this field.

Fourth, there is a lack of preparation for the genetic era in the provider community. A recent survey by the American Medical Association (Chicago) and Medco (St Louis) found that most medical schools have only recently begun training their medical students in genetics, and only $29 \%$ of physicians reported any training in genetics. ${ }^{8}$ Moreover, $98 \%$ of surveyed physicians believed that genetics was important for making clinical decisions, but only $10 \%$ were actually using genetic information in their practices. Meanwhile, the number of genetic counselors and physicians with specialty training in genetics is already inadequate $\left(\sim 3,000\right.$ nationwide for each category). ${ }^{9}$ Thus, providers will be increasingly confronted with genetic data or opportunities for useful genetic testing but, lacking adequate genetics education and unable to access genetic specialists, may commit the types of diagnostic errors that could lead to liability.

Fifth, a diverse set of recent doctrinal shifts and noteworthy decisions are expanding the liability risks for physicians with reference to genetic testing. For example, the traditional local custom standard for medical malpractice is migrating gradually in some jurisdictions toward a more objective "reasonableness" standard or a national standard of care. This trend will undercut physicians' reliance on local custom as a defense and will create increased risk for providers who are without ready access to the requisite genetic expertise. Moreover, new obligations may be imposed on physicians, such as a duty to disclose risks to relatives of patients or to recontact patients to convey new insights on previously collected genetic data.

To be sure, there are some countervailing factors that will tend to protect physicians from genetic malpractice claims. Many states have been imposing procedural hurdles and damages caps in medical malpractice cases generally, which will also impede many genetic malpractice cases. Moreover, plaintiffs' attorneys tend to be risk averse against bringing novel legal claims, which for the time being at least includes most genetic malpractice lawsuits. And finally, just as many physicians lack detailed knowledge about genetics, so too do most trial lawyers, further deterring them from bringing such suits.
Notwithstanding these deterrents, genetic malpractice lawsuits are already being brought, and to the extent they succeed, will quickly encourage waves of copycat suits. Now is a critical time to take preventive steps before runaway liability makes any such measures too little and too late. Physician education about genetics, both for the general practitioner and for specialists in medical genetics, will be essential in the long term, and some recent initiatives are moving, perhaps too slowly, in that direction. Clear, credible, evidence-based, and up-to-date clinical guidelines specifying when and where genetic testing can be useful and where it is not (at least at the present time) are needed to help guide clinical judgment and may help provide a partial shield against malpractice liability. ${ }^{10}$

Perhaps most importantly, individual providers must take note of the rapidly changing clinical landscape and take appropriate precautions to avoid becoming the next headline for personalized medicine liability. This does not mean resorting to defensive medicine and recommending genetic testing when it is not clinically justified but rather understanding where genetic testing might arguably be applicable to individual patients and carefully documenting decisions and the associated rationales for recommending or not recommending genetic testing for each patient.

\section{ACKNOWLEDGMENTS}

This commentary derives from research funded by the National Institutes of Health's National Human Genome Research Institute grant 1 R01 HG006145-01A1.

\section{DISCLOSURE}

Marchant's work has been funded by the National Institutes of Health. He has received honoraria in the past $3 \mathrm{y}$ (unrelated to this work) from the Federal Judicial Center, the State Courts of Minnesota, Arkansas, lowa, New Mexico, Nevada, and Oklahoma, G2 Conferences, North American Insulation Manufacturers Association, and the Asphalt Roofing Manufacturers Association.

\section{REFERENCES}

1. Downs v. Trias, 49 A.3d 180 (Conn. 2012).

2. Levy v. Legacy Health System, 2012 WL 1646980 (Or.Cir. 2012).

3. Scholz v. Kaiser Foundation Hospital, RG12614636, Alameda Sup. Ct. (filed Jan. 30, 2012)

4. Marchant GE, Lindor RA, Campos-Outcalt DE. Physician liability: the next big thing for personalized medicine? Personal Med 2012;8:457-467.

5. De Ville K. Medical malpractice in twentieth century United States. The interaction of technology, law and culture. Int J Technol Assess Health Care 1998;14:197-211.

6. Grady MF. Why are people negligent? technology, nondurable precautions, and the medical malpractice explosion. Northwest U Law Rev 1988;82:293-334.

7. Lazarou J, Pomeranz BH, Corey PN. Incidence of adverse drug reactions in hospitalized patients: a meta-analysis of prospective studies. JAMA 1998;279:1200-1205

8. Stanek EJ, Sanders CL, Taber KA, et al. Adoption of pharmacogenomic testing by US physicians: results of a nationwide survey. Clin Pharmacol Ther 2012;91:450-458.

9. Haga SB, Burke W, Agans R. Primary-care physicians' access to genetic specialists: an impediment to the routine use of genomic medicine? Genet Med 2013;15:513-514.

10. Mello MM. Of swords and shields: the use of clinical practice guidelines in medical malpractice litigation. U Penn Law Rev 2000;149:645-710. 